\title{
Effect of maternal dry period length on colostrum immunoglobulin content and on natural and specific antibody titers in calves
}

\author{
N. Mayasari, ${ }^{*} \dagger^{1}$ G. de Vries Reilingh, ${ }^{*}$ M. G. B. Nieuwland, ${ }^{*}$ G. J. Remmelink, $\ddagger$ H. K. Parmentier, ${ }^{*}$ B. Kemp, ${ }^{*}$ \\ and A. T. M. van Knegsel* \\ *Adaptation Physiology Group, Department of Animal Science, Wageningen University, PO Box 338, 6700 AH Wageningen, the Netherlands \\ †Faculty of Animal Husbandry, Universitas Padjadjaran, 3636, Bandung, Indonesia \\ fLivestock Research, Wageningen University and Research Centre, PO Box 338, 6700 AH Wageningen, the Netherlands
}

\section{ABSTRACT}

The objective was to study the effect of dry period length in dairy cows on immunoglobulin content and natural antibodies (NAb) titers in colostrum, growth, and plasma natural and specific antibody titers in plasma of calves. Holstein-Friesian dairy cows $(\mathrm{n}=167)$ were randomly assigned to 3 dry period lengths $(0,30$, or $60 \mathrm{~d}$ ). Colostrum production, concentration of colostrum IgG and IgM, and titers of NAb (isotypes IgG and IgM) binding keyhole limpet hemocyanin (KLH) and human serum albumin (HuSA) in colostrum were measured. Female calves were immunized with both KLH and HuSA at wk 6 and 10 of life. Titers of NAb and specific antibody (SpAb) for isotypes $\operatorname{IgG}$, IgM, and total immunoglobulin ( $\operatorname{IgT}$ ) binding KLH or HuSA were determined in plasma of female calves. Primary and secondary antibody responses to KLH or HuSA from wk 6 and 10 were expressed as the increase in antibody titers to wk 10 and 11 of life after primary and secondary challenges, respectively. Pregnancy length for cows with a 0-d dry period was $3 \mathrm{~d}$ shorter compared with cows with a 30- or 60-d dry period. Birth weight of calves from cows with a 0-d dry period was lower compared with calves from cows with a 30-d dry period. Growth of calves until 12 wk of life was not affected by dry period length. Colostrum production and $\operatorname{IgG}$ and IgM concentration in colostrum were lower for cows with a 0-d dry period than a 60-d dry period. Natural IgG and IgM titers binding KLH or HuSA were lower in colostrum from cows with a 0 -d dry period compared with cows with a 60-d dry period. Natural antibody titers (IgG, IgM, and IgT) binding KLH or HuSA in plasma were lower during the first 2 wk of life for calves from cows with a 0-d dry period compared with calves from cows with a 30- or 60-d dry period. After primary and secondary immunization of

Received August 18, 2014.

Accepted February 18, 2015.

${ }^{1}$ Corresponding author: novi.mayasari@wur.nl calves with KLH and HuSA, SpAb titers of calves were not affected by dry period length. After secondary immunization, the response of IgG and IgT binding KLH was higher in plasma of calves from cows with a $0-\mathrm{d}$ dry period. The results of this study demonstrate that, although omission of the dry period of dairy cows leads to lower plasma NAb titers in calves during the first 2 wk of life, SpAb titers in calves were not affected and even the secondary antibody responses were enhanced compared with calves from cows with a 30- or 60-d dry period.

Key words: continuous milking, colostrum, antibodies, calf

\section{INTRODUCTION}

Omission of the dry period of cows results in better energy balance and metabolic health in the next lactation (Andersen et al., 2005; Rastani et al., 2005). Omission of the dry period is controversial because of a potential decrease in milk production in the subsequent lactation (Annen et al., 2004; Santschi et al., 2011a). A meta-analysis including 24 randomized controlled trials (van Knegsel et al., 2013) reported that shortening or omitting the dry period reduced milk production and increased milk protein content. In addition, shortening the dry period tended to reduce the incidence of ketosis in the subsequent lactation. Earlier studies showed that shortening the dry period to 4 wk did not affect colostrum immunoglobulin content (Annen et al., 2004; Rastani et al., 2005; Watters et al., 2008; Klusmeyer et al., 2009), pregnancy length (Santschi et al., 2011b), and birth weight of calves (Rastani et al., 2005; Pezeshki et al., 2007) compared with a dry period of 8 wk. Omission of the dry period, however, reduced colostrum immunoglobulin content (Annen et al., 2004; Rastani et al., 2005; Klusmeyer et al., 2009; Verweij et al., 2014), which may affect the immune competence of the calf. Adequate and sufficient passive immune transfer of maternal antibodies via colostrum intake may improve the immune competence of calves and would 
reduce the risk of diseases and infections during the preweaning period (Oliveira et al., 2010).

Natural antibodies (NAb) may play an important role in the development of immune competence. Natural antibodies are part of the innate immune system (Matter and Ochsenbein, 2008; Vollmers and Brändlein, 2009) and can be defined as antibodies present in healthy animals under the absence of antigen stimulation (Avrameas, 1991; Baumgarth et al., 2005), as opposed to specific antibodies (SpAb), which are raised to antigens after immunization. Natural antibodies are polyreactive with low affinity binding with various antigens (Casali and Notkins, 1989). Natural antibodies link innate and adaptive immunity, as they target antigens to the splenic marginal zone enhancing T-cell and T-cell-dependent antibody responses (Matter and Ochsenbein, 2008), and activate complement activity. Zinkernagel (2012) proposed that NAb form an important protection for resistance to infection. In chickens, $\mathrm{NAb}$ binding Megathura crenulata-derived keyhole limpet hemocyanin (KLH) were related to a higher probability of survival during the laying period (Star et al., 2007; Sun et al., 2011). In mammals (Tomer and Shoenfeld, 1988; Thornton et al., 1994; Ochsenbein et al., 1999) and birds (Lammers et al., 2004; Parmentier et al., 2004), various specific humoral immune responses are enhanced by high NAb titers or are positively correlated with high NAb titers. Conversely, high NAb levels might interfere with or prevent subsequent $\mathrm{SpAb}$ responses (Parmentier et al., 2008), whereas low NAb levels might facilitate or initiate higher $\mathrm{SpAb}$ responses (Sinyakov et al., 2002).

Natural antibodies were found in plasma of newborn calves (Srinivasan et al., 1999). In dairy cows, calves obtain maternal antibodies passively from the dam through colostrum. Natural antibodies in plasma of newborn calves were lower than in adult cows (Srinivasan et al., 1999) and NAb titers differ widely among adults (Srinivasan et al., 1999; Ploegaert et al., 2011). In addition, titers of NAb binding KLH or LPS were related to the energy balance of dairy cows in early lactation (van Knegsel et al., 2007). Knowledge on the effect of shortening or omitting the dry period of dairy cows on NAb in colostrum and the consequences for immune competence and development of calves is, however, absent.

As calves obtain passive immunity via colostrum, it was hypothesized that management or dietary strategies that affect immunoglobulin content in colostrum may affect immune competence of calves. The first objective of the present study was to evaluate the effect of dry period length in dairy cows on immunoglobulin content and NAb titers in colostrum, and growth and plasma $\mathrm{NAb}$ and SpAb titers of calves. The second objective was to study the responses of total immunoglobulin $(\operatorname{Ig} \mathbf{T})$ and the isotypes $\operatorname{IgG}$ and IgM binding KLH and human serum albumin (HuSA) after primary and secondary immunization in these calves at wk 6 and 10 , respectively.

\section{MATERIALS AND METHODS}

\section{Experimental Design, Animals, and Colostrum Sampling}

The Institutional Animal Care and Use Committee of Wageningen University approved the experimental protocol. Holstein-Friesian dairy cows $(\mathrm{n}=167)$ were selected from the Dairy Campus Research dairy herd (WUR Livestock Research, Lelystad, the Netherlands), blocked for parity, calving date, milk yield, and BCS, and randomly assigned to treatments. Cows enrolled in our study were clinically healthy and had SCC in milk $<250 \times 10^{3}$ cells $/ \mathrm{mL}$. Treatments consisted of 3 dry period lengths, 0,30 , or $60 \mathrm{~d}$, and 2 diets in early lactation (glucogenic or lipogenic) in a $3 \times 2$ factorial design. The experiment started with 60 primiparous and 107 multiparous cows. Cows were housed in a freestall with slatted floor and cubicles and milked twice daily (0500 and $1630 \mathrm{~h}$ ).

\section{Diets}

Diet composition was described previously (van Knegsel et al., 2014). Prepartum, dry cows received a dry cow diet and lactating cows received a lactation diet supporting $25 \mathrm{~kg}$ of milk. From $10 \pm 5 \mathrm{~d}$ prepartum, cows were fed $1 \mathrm{~kg} / \mathrm{d}$ of the experimental concentrate (glucogenic or lipogenic). Postpartum, all cows received $1 \mathrm{~kg}$ of experimental concentrate, which was increased stepwise by $0.5 \mathrm{~kg} / \mathrm{d}$ until concentrate supply reached $8.5 \mathrm{~kg} / \mathrm{d}$ at d 17 postpartum. Experimental concentrates were provided by a computerized feeder located in the freestall. In addition, lactating cows received $1 \mathrm{~kg} / \mathrm{d}$ of standard lactation concentrate in the milking parlor. Forage did not differ between diets, was supplied ad libitum, and consisted of grass silage, corn silage, wheat straw, and a protein source (rapeseed meal or soybean meal) in a ratio of 39:25:25:11 (DM basis). Postpartum, forage consisted of grass silage, corn silage, straw, and a protein source (rapeseed meal or soybean meal) in a ratio 51:34:2:13 (DM basis).

\section{Management of Calves}

Immediately after birth, calves were removed from dam. When calves were born between 2200 until 0500 $\mathrm{h}(\mathrm{n}=42)$ they were removed from the dam at 0500 
h. Calves were weighed and within $24 \mathrm{~h}$ of life they received $4 \mathrm{~L}$ of colostrum in 2 portions from their mother. Secretion of the first milk was collected and weighed directly after calving, except when the cow calved between 2200 until $0500 \mathrm{~h}(\mathrm{n}=42)$. Colostrum obtained after parturition was agitated and colostrum samples $(10 \mathrm{~mL})$ were stored at $-20^{\circ} \mathrm{C}$. At $24 \mathrm{~h}$ after birth, calves were fed with milk replacer $(\mathrm{CP}=22 \%$ and fat $=17 \% ; 2 \times / \mathrm{d}, 2 \mathrm{~L})$. After $2 \mathrm{~d}$, calves were moved to the calf-raising farm and were also fed milk replacer twice a day until 60-d of life. After the first week of life, all calves were fed the same mixture of hay and grains (Agrifirm Feed, Apeldoorn, the Netherlands) based on requirements for preweaned Holstein calves. At $60 \mathrm{~d}$ of life, calves were weaned from milk replacer. From $60 \mathrm{~d}$ of life on, calves received a diet based on requirement for weaned Holstein calves. During first 2 wk of life, calves were housed in individual hutches located approximately $60 \mathrm{~cm}$ apart. After $2 \mathrm{wk}$, calves were kept in groups of 6 to 8 calves with straw bedding. Body weight of female calves was recorded at birth and wk 2 , $4,6,8,10$, and 12 after birth. Disease incidences were recorded.

\section{Blood Sampling and Immunization}

Blood samples of female calves $(n=63)$ were taken from the jugular vein immediately after birth and every Wednesday in wk 1, 2, 4, 6, 7, 8, 10,11, and 12 of life in Vacutainer tubes $(10 \mathrm{~mL}$; Becton Dickinson and Co., Franklin Lakes, NJ) containing heparin to determine titers of total (IgT), IgG, and IgM natural and specific antibody titers binding KLH or HuSA. Blood samples were centrifuged at $3,000 \times g$ at $4^{\circ} \mathrm{C}$ for $15 \mathrm{~min}$ immediately after sample collection, and plasma was stored at $-20^{\circ} \mathrm{C}$ until analysis. Female calves were immunized twice with a combination of both KLH and HuSA. Solutions of KLH and HuSA were prepared by dissolving $2 \mathrm{mg}$ of KLH (H7017, Sigma Aldrich Co., St Louis, MO) and $0.2 \mathrm{mg}$ of HuSA (A8763, Sigma Aldrich) in $2.5 \mathrm{~mL}$ of PBS $(0.1 \mathrm{M}, \mathrm{pH}=7.2)$. Calves received a 2.0-mL i.m. injection in the neck at wk 6 of life and a second injection at wk 10 of life.

\section{Analysis of Immunoglobulin Concentration in Colostrum}

Colostrum was not sampled during weekends. Total concentration of IgG and IgM in colostrum was determined by an indirect ELISA method using the Bovine IgG ELISA Quantitation Kit (Cat. No. E10-118, Bethyl Laboratories Inc., Montgomery, TX), and the Bovine IgM ELISA Quantitation Kit (Cat. No. E10-101,
Bethyl Laboratories). Kit performance was optimized for the stated protocol using affinity purified sheep anti-bovine $\operatorname{Ig} G$ heavy chain or IgM-coating antibody, bovine reference serum and horseradish peroxidase (PO) conjugated sheep anti-bovine IgG-heavy chain or IgM-detection antibody. Standard dilutions from 500 to $7,800 \mathrm{ng} / \mathrm{mL}$ of bovine $\mathrm{IgG}$ and 1,000 to $15,625 \mathrm{ng} / \mathrm{mL}$ of bovine IgM were used according to manufacturer's procedures.

\section{Analysis of NAb and SpAb in Colostrum and Plasma}

Natural antibody titers binding KLH and HuSA in plasma of female calves were measured by indirect ELISA as outlined by van Knegsel et al. (2007). The same ELISA procedures were also used to measure NAb titers in colostrum and SpAb titers binding KLH and HuSA in plasma of female calves. Plates were coated with $4 \mu \mathrm{g} / \mathrm{mL}$ of KLH or $4 \mu \mathrm{g} / \mathrm{mL}$ of HuSA $(100 \mu \mathrm{L} /$ well). Natural antibody of the IgG isotype in colostrum were detected using 1:40,000 diluted sheep polyclonal anti-bovine IgG-heavy chain conjugated to horseradish PO (Cat. No. E10-118P, Bethyl Laboratories). Natural antibody of the IgM isotype in colostrum was detected using 1:20,000 diluted rabbit polyclonal anti-bovine IgM-whole molecule conjugated to horseradish PO (Cat. No. A10-100P, Bethyl Laboratories). Serial dilutions for isotypes (IgG and IgM) in colostrum samples started at 1:10 (8 steps). Natural antibodies and SpAb isotypes IgM and IgG in plasma were detected either using 1:40,000 diluted sheep polyclonal anti-bovine IgG-heavy chain conjugated to horseradish PO (Cat. No. E10-118P, Bethyl Laboratories), 1:20,000 diluted rabbit polyclonal anti-bovine IgM whole molecule conjugated to horseradish PO (Cat. No. A10-100P, Bethyl Laboratories), or 1:20,000 diluted rabbit anti-bovine IgG heavy and light chain conjugated to horseradish PO (Cat. No. A10-102P, Bethyl Laboratories) for IgT. Serial dilutions for isotypes (IgG, $\operatorname{IgM}$, and $\operatorname{IgT}$ ) in plasma samples started at 1:40 (4 steps). Titers were expressed as $\log 2$ values of the dilutions that gave an extinction closest to $50 \%$ of Emax, where Emax represents the highest mean extinction of a standard positive (pooled) serum present on every microtiter plate (Ploegaert et al., 2007). Preliminary analysis showed the highest response of antigen SpAb after primary and secondary immunizations in wk 10 and 11 of life, respectively. Therefore, response to primary antigen challenges was defined by subtracting the SpAb titers for isotype $\operatorname{IgG}$, $\operatorname{IgM}$, and $\operatorname{IgT}$ binding KLH and HuSA at wk 10 after primary immunization with titers at wk 6. Response to secondary antigen challenges was defined by subtracting the SpAb titers for isotype IgG, 
IgM, and IgT binding KLH and HuSA at wk 11 after secondary immunization with titers at wk 10 .

\section{Statistical Analyses}

Three pairs of twins (4 calves from cows with a 60-d dry period and 2 calves from cows with a 0 -d dry period) and 3 stillborn calves (2 calves from cows with a 0 -d dry period and 1 calf from cow with a 60 -d dry period) were excluded from the analysis. Three female calves, 1 calf from a cow with a 30-d dry period and 2 calves from cows with a $0-d$ dry period, died in the rearing unit before wk 6 and were removed from analysis. The ANOVA PROC MIXED procedure (SAS version 9.2, SAS Institute Inc., Cary, NC; Littell et al., 1996) was used to analyze colostrum immunoglobulin content, pregnancy length, birth weight, growth, and plasma antibody titers. Preliminary analysis showed no effect of diet on colostrum, plasma, and growth variables; therefore, diet was excluded from the analysis. Colostrum immunoglobulin content, NAb titer binding $\mathrm{KLH}$ or HuSA in colostrum, calf growth, and the response after primary antibody challenge at $6 \mathrm{wk}$ and secondary antibody challenge at $10 \mathrm{wk}$ were analyzed with dry period length $(0,30$, or $60 \mathrm{~d})$, parity $(2,3$, or $>3$ ), and their interaction included as fixed effect (model 1). Preliminary analysis showed no difference between concentrations of $\mathrm{IgG}$ and $\operatorname{IgM}$ in colostrum collected directly after calving and concentration of IgG and IgM in colostrum from cows which calved during 2200 to $0500 \mathrm{~h}(\mathrm{n}=42)$. Thus, both colostrum samples from cows which calved during night and cows which calved during the day were included in the analysis. Pregnancy length and birth weight for all calves were analyzed with dry period length $(0,30$, or $60 \mathrm{~d})$, parity $(2,3$, or $>3)$, sex, and interactions included as fixed effects (model 2). Natural antibody titers (wk 0 until 6) and SpAb titers after primary (wk 6 until 10) and secondary immunization (wk 10 until 12) in plasma were analyzed with dry period length $(0,30$, or $60 \mathrm{~d})$, parity $(2,3$, or $>3)$, week (1-12), and interactions included as fixed effects (model 3). In model 3, calf was considered as the repeated subject. A first-order auto-regressive structure $[\mathrm{AR}(1)]$ was the best fit and was used to account for within-calf variation. For comparison of dry period length effects, $P$-values are presented after a Bonferroni adjustment. Model assumption regarding normality of residuals was evaluated by examining whether skewness and kurtosis were close to 0. Values are presented as LSMEANS with their pooled SEM, unless otherwise stated. Pearson correlation coefficient (PROC CORR in SAS) were used to test the correlation between $\mathrm{NAb}$ titers (IgG and IgM) binding $\mathrm{KLH}$ or HuSA in colostrum and NAb titers (IgG and IgM) binding KLH or HuSA in plasma of calves.

\section{RESULTS}

\section{Colostrum}

Cows with a 60-d dry period had greater colostrum production at first milking after calving compared with cows with a 0 - or $30-\mathrm{d}$ dry period ( 7.7 vs. 5.3 vs. 5.1 $\pm 0.6 \mathrm{~kg}$ for cows with 60 - vs. 30 - vs. 0 -d dry period, respectively; $P<0.01)$. Cows with a 0 -d dry period had lower $\operatorname{IgG}$ and IgM concentration in colostrum (Figure 1a) compared with cows with a 30- or 60-d dry period. There were no differences in IgG or IgM concentration in colostrum between cows with a 30- or 60-d dry period. Concentration of IgG in colostrum increased with parity ( 20.9 vs. 27.0 vs. $30.8 \pm 2.2 \mathrm{mg} / \mathrm{mL}$ for parity 2 vs. 3 vs. $>3$, respectively; $P=0.01$ ). Titers for IgG and IgM binding KLH and HuSA in colostrum were lower for cows with a 0-d dry period compared with cows with a 30- or 60-d dry period (Figure 1b). Natural antibody titers in colostrum increased with parity, except natural IgM binding HuSA.

\section{Birth Weight and Growth of Calves}

Calves from cows with a 0 -d dry period were born 3 d earlier $(P=0.01)$ and had a lower birth weight $(P$ $=0.04$ ) compared with calves from cows with a 30or 60-d dry period (Table 1). Omitting the dry period resulted in lower birth weight of the male calves (43.7 vs. 46.5 vs. $46.2 \pm 0.8 \mathrm{~kg}$ for 0 - vs. 30 - vs. 60 -d dry period, respectively; $P=0.02)$ but did not affect birth weight of the female calves $(42.3 \pm 0.8 \mathrm{~kg})$. Cows with a 0 -d dry period had shorter pregnancy length and lower birth weight. Pregnancy length showed positive relation with birth weight of calves from cows with a 0-d dry period. Body weight of the female calves before first immunization at wk 6 was not different between dry period lengths ( 56.9 vs. 60.6 vs. $58.9 \pm 0.2 \mathrm{~kg}$ for 0 - vs. 30 - vs. $60-\mathrm{d}$ dry period, respectively; $P=0.12$ ). Growth of female calves from d 0 until wk 12 of life and live weight of female calves at wk 12 (data not shown) were not different between dry period lengths of the cows $(P$ $=0.19$ and $P=0.18$, respectively). Disease incidence of calves did not differ among dry period lengths.

\section{NAb Titers in Plasma of Calves}

Calves from cows with a 0 -d dry period had lower natural $\operatorname{IgG}, \operatorname{IgM}$, and $\operatorname{IgT}$ in plasma compared with calves from cows with a 60-d dry period (Table 2), ex- 
Table 1. Birth weight, pregnancy length, and growth of calves during the first 12 wk of life from cows with different dry period lengths $(0,30$, or $60 \mathrm{~d}$; LSM)

\begin{tabular}{|c|c|c|c|c|c|c|c|c|}
\hline \multirow[b]{2}{*}{ Performance } & \multicolumn{3}{|c|}{ Dry period length } & \multirow[b]{2}{*}{ SEM } & \multicolumn{4}{|c|}{$P$-value ${ }^{1}$} \\
\hline & 0 & 30 & 60 & & $\mathrm{D}$ & $\mathrm{P}$ & S & $\mathrm{D} \times \mathrm{P}$ \\
\hline Calves (no.) & 54 & 54 & 51 & & & & & \\
\hline Birth weight, all $^{2}(\mathrm{~kg})$ & $42.9^{\mathrm{a}}$ & $44.7^{\mathrm{b}}$ & $44.4^{\mathrm{ab}}$ & 0.55 & 0.04 & 0.27 & $<0.01$ & 0.23 \\
\hline Pregnancy length (d) & $278^{\mathrm{a}}$ & $280^{\mathrm{b}}$ & $281^{\mathrm{b}}$ & 0.63 & 0.01 & 0.12 & 0.25 & 0.82 \\
\hline $\operatorname{Growth}^{3}(\mathrm{~kg} / \mathrm{d})$ & 0.6 & 0.7 & 0.7 & 0.02 & 0.19 & 0.04 & $\mathrm{NM}^{4}$ & 0.90 \\
\hline
\end{tabular}

${ }^{\mathrm{a}, \mathrm{b}}$ Values in the same row with different superscripts differ $(P<0.05)$.

${ }^{1} \mathrm{D}=$ dry period; $\mathrm{P}=$ parity; $\mathrm{S}=$ sex.

${ }^{2}$ Birth weight of all calves (male and female) excluding twins and stillborn calves.

${ }^{3}$ Growth of female calves. Three calves were removed from the analysis because they died in the rearing unit before wk 6 of life.

${ }^{4} \mathrm{NM}=$ not included in the model.

cept for IgG binding HuSA. Natural antibody titers for calves from cows with a 0 -d dry period were specifically lower immediately after calving (wk 0), and in wk 1 and 2 (Figure 2). Natural IgT binding KLH and HuSA in plasma increased with parity (2.2 vs. 2.5 vs. $3.0 \pm$ 0.2 and 1.4 vs. 1.9 vs. $1.9 \pm 0.1$ for parity 2 vs. 3 vs. $>3$ for IgT binding KLH and HuSA, respectively). Natural IgT binding KLH and HuSA in plasma of calves were affected by dry period $\times$ parity interaction $(P<0.01$ and $P=0.02$, respectively). Titers of natural $\operatorname{IgG}$ and IgM binding KLH and HuSA in colostrum correlated positively with titers of natural IgG and IgM binding KLH and HuSA in plasma of calves at calving $(\mathrm{r}=$ $0.73, P<0.01$ and $\mathrm{r}=0.70, P<0.01$ for $\operatorname{IgG}$ and IgM binding $\mathrm{KLH}$, respectively; $\mathrm{r}=0.41, P<0.01$ and $\mathrm{r}=0.65, P<0.01$ for IgG and IgM binding HuSA, respectively). There were no correlations between $\mathrm{NAb}$ titers present in colostrum and NAb titers in plasma of calves after 2 wk.

\section{Primary and Secondary Antibody Responses to $K L H$ and HuSA}

Primary and secondary SpAb titers for all isotypes binding KLH and HuSA in plasma of calves did not differ between dry period lengths (Table 3). All SpAb titers (IgG, IgM, and IgT) binding KLH or HuSA in plasma of calves increased following primary and secondary immunization (Figure 2), except for IgM binding KLH or HuSA after the secondary immunization. Specific anti-
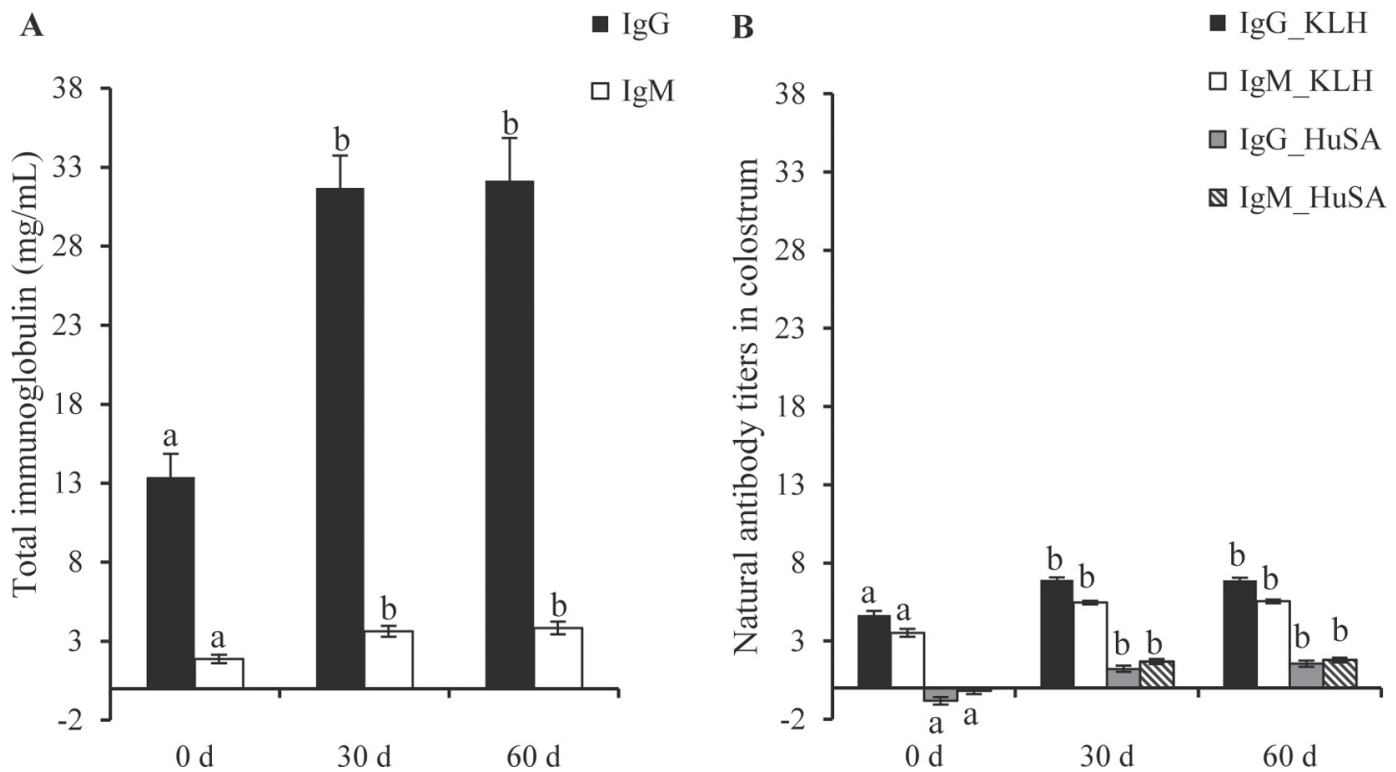

Figure 1. Concentration of $\operatorname{IgG}$ and $\operatorname{IgM}(\mathrm{A})$ and natural antibodies (NAb) for isotype $\operatorname{IgG}$ and $\operatorname{IgM}$ titers binding keyhole limpet hemocyanin (KLH) and human serum albumin (HuSA; B) in colostrum from cows with 3 different dry period lengths $(0,30$, or $60 \mathrm{~d})$. Values are means $( \pm$ SEM) per dry period length. 
Table 2. Natural antibody titers [IgG, IgM, and total immunoglobulin (IgT)] binding keyhole limpet hemocyanin (KLH) and human serum albumin (HuSA) from wk 0 until 6 in plasma of calves from cows with different dry period lengths $(0,30$, or $60 \mathrm{~d}$; LSM)

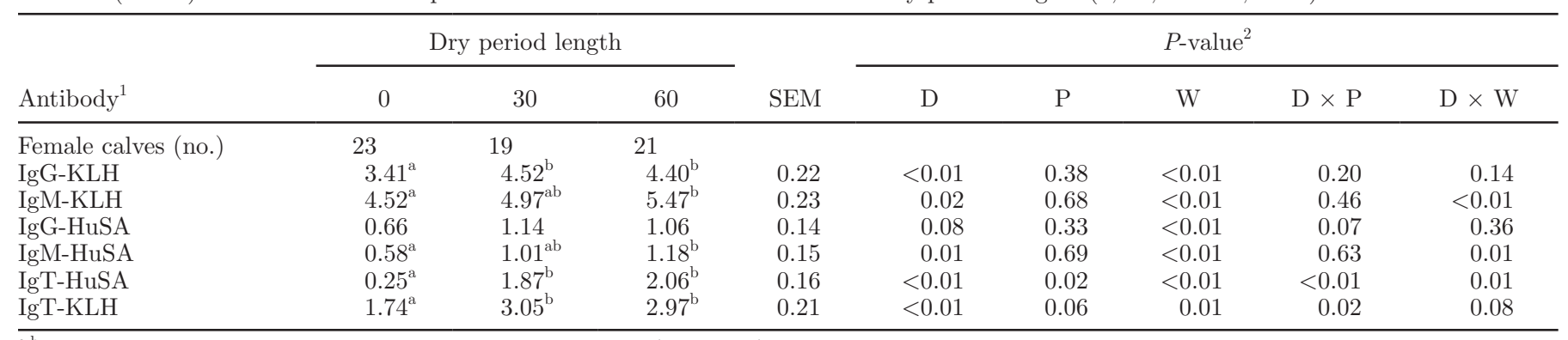

${ }^{a, b}$ Values in the same row with different superscripts differ $(P<0.05)$.

${ }^{1}$ Antibody names are combination of immunoglobulin isotype and antigen abbreviation.

${ }^{2} \mathrm{D}=$ dry period; $\mathrm{P}=$ parity; $\mathrm{W}=$ week.

body titers for isotype $\operatorname{IgG}$ and IgT binding HuSA in calves increased with parity of the cows. After primary immunization, calves from younger cows (parity 2) had lower specific IgG titers binding HuSA (2.0 vs. 3.0 vs. $2.8 \pm 0.3$ for parity 2 vs. 3 vs. $>3$, respectively; $P=$ 0.05 ) and lower IgT titers binding HuSA (2.8 vs. 4.4 vs. $4.0 \pm 0.3$ for parity 2 vs. 3 vs. $>3$, respectively; $P<$ 0.01) compared with calves from older cows. After secondary immunization, calves born from younger cows had lower specific IgG titers binding HuSA (3.7 vs. 5.2 vs. $5.0 \pm 0.4$ for parity 2 vs. 3 vs. $>3$, respectively; $P=$ 0.04 ) and $\operatorname{IgT}$ titers binding HuSA (4.9 vs. 7.0 vs. 6.4 \pm 0.5 for parity 2 vs. 3 vs. $>3$, respectively; $P=0.01$ ) compared with calves from older cows. After secondary immunization, a dry period length $\times$ week interaction was noted for titers of $\operatorname{IgG}(P<0.01)$ and $\operatorname{IgT}$ binding $\mathrm{KLH}(P=0.02)$. Calves born from cows with a 0 -d dry period had higher plasma titers of specific IgG binding $\mathrm{KLH}$ and IgT binding KLH compared with calves born from cows with a 30- or a 60-d dry period.

After primary antigen challenge, the $\operatorname{Ig} G$ binding $\mathrm{KLH}$ response tended to be higher for the calves from cows with a 0 -d dry period compared with calves from cows with a 30 - or 60 -d dry period (Table 4 ). After primary antigen challenge, IgT binding KLH response was higher for the calves from cows with a 0-d dry period compared with calves from cows with a 30- or 60-d dry period. Also, secondary IgG and IgT responses binding $\mathrm{KLH}$ were enhanced in calves born from mothers with a 0-d dry period compared with a $30-$ or $60-d$ dry period. The responses of SpAb in plasma of calves after both primary and secondary immunization between a 30- and a 60-d dry period were not different.

\section{DISCUSSION}

The present study shows that a 0-d dry period for dairy cows resulted in lower NAb titers binding KLH or
HuSA in calves in the first 2 wk of life compared with calves from cows with a 30- or 60-d dry period. Specific antibody titers binding KLH and HuSA after primary immunization in wk 6 or secondary immunization in wk 10 of life did not differ between calves born from mothers with different dry period lengths. After secondary immunization, however, calves from cows with a 0-d dry period showed higher titers of $\operatorname{IgG}$ and $\operatorname{Ig} \mathrm{T}$ binding KLH compared with calves from cows with a 30- or 60-d dry period. This suggests that specific humoral immune competence of calves from cows with a $0-d$ dry period length was not negatively affected.

Natural antibodies detected in plasma of calves immediately after birth are likely derived from colostrum, as calves are born without antibodies in blood (Srinivasan et al., 1999). In our study, NAb titers in colostrum were positively correlated with NAb titers in plasma of calves during the first 2 wk of life. In addition, natural IgG and IgM binding to KLH and HuSA in plasma of calves was correlated positively with natural $\mathrm{IgG}$ and IgM binding to KLH and HuSA in colostrum. In the current study, concentrations of IgG and IgM and natural IgG and IgM binding KLH or HuSA in colostrum were reduced when cows had a 0-d dry period compared with cows with a 30- or 60-d dry period. The present study concurs with results of earlier studies (Annen et al., 2004; Rastani et al., 2005; Klusmeyer et al., 2009; Verweij et al., 2014), which detected a reduction in IgG concentration in colostrum after omission of the dry period compared with a conventional dry period. Concentration of IgG was lower in present study compared with earlier studies (Annen et al., 2004; Rastani et al., 2005; Watters et al., 2008; Klusmeyer et al., 2009). In those earlier studies, single radial immunodiffusion assays were used to assess antibody level in colostrum (Annen et al., 2004; Rastani et al., 2005; Watters et al., 2008; Klusmeyer et al., 2009). In the present study, immunoglobulin concentration in colostrum was as- 

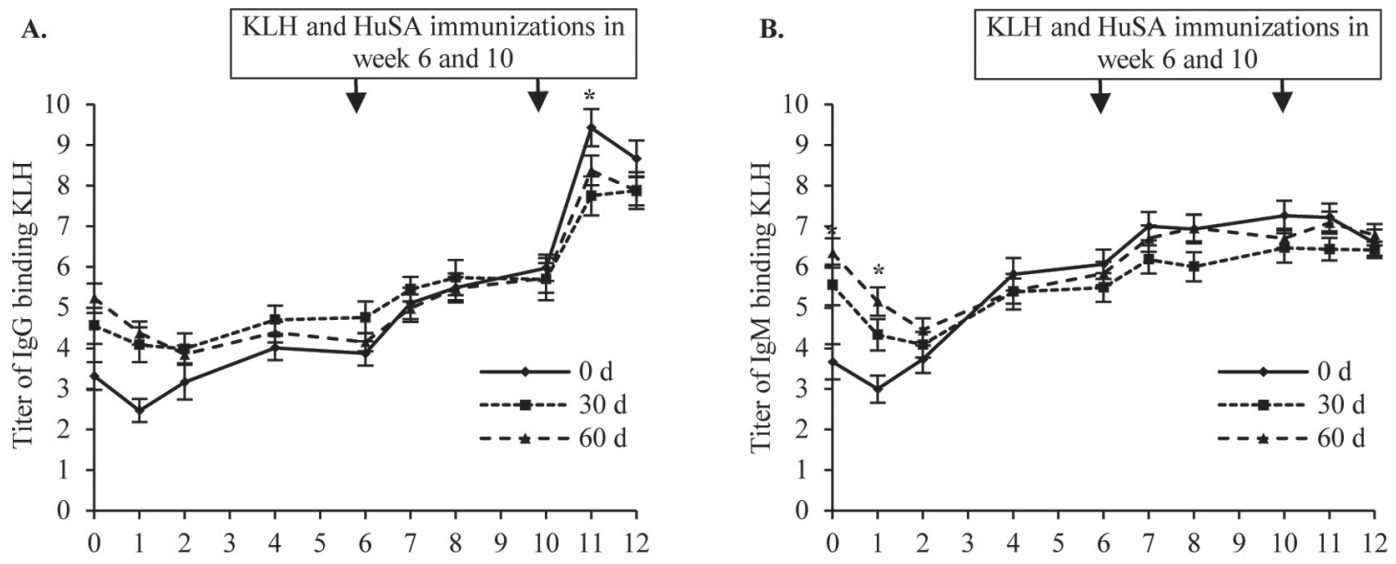

C.

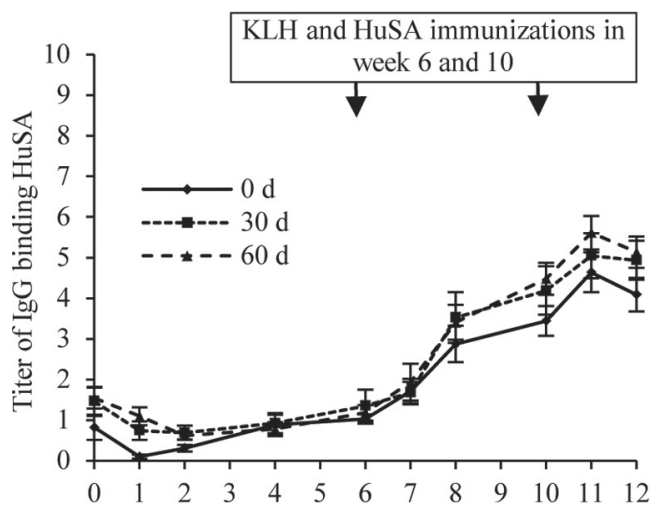

D.

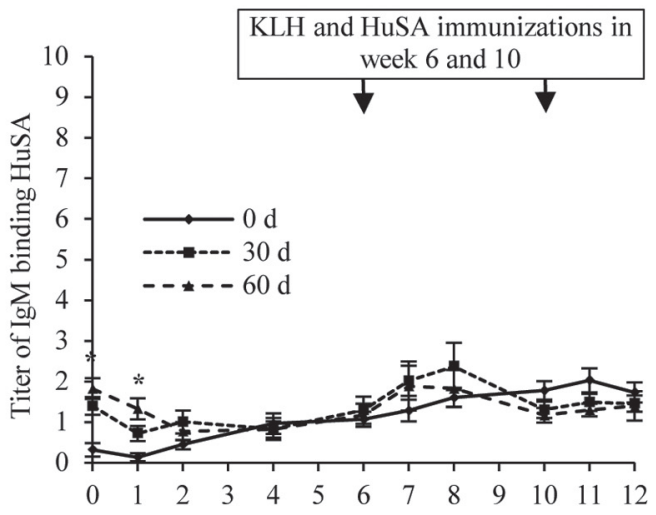

E.

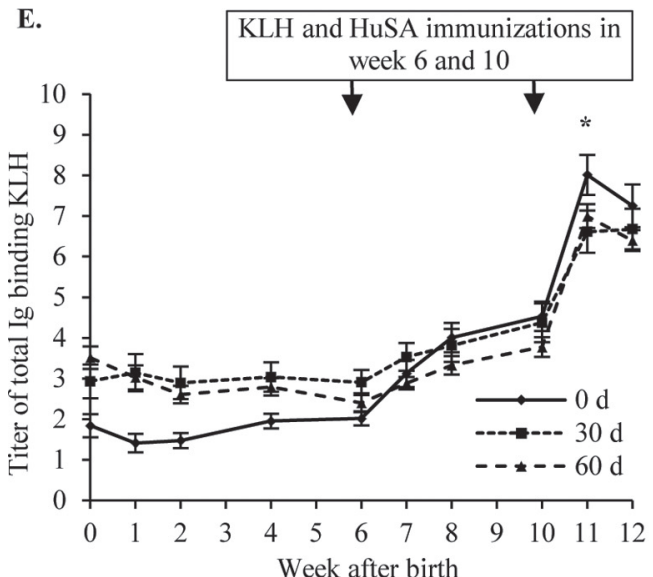

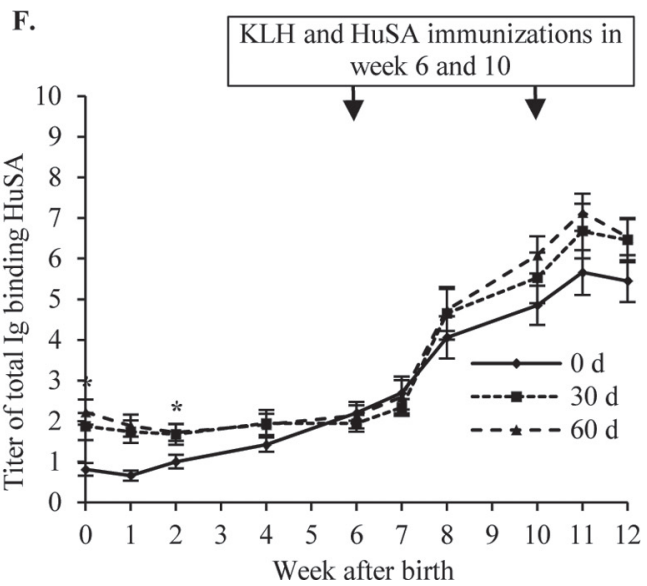

Figure 2. Natural antibodies (wk 0 to 6 ) and specific antibodies (after primary and secondary immunization) for IgG, IgM, and total immunoglobulin (IgT) titers binding keyhole limpet hemocyanin (KLH; A, C, and E) and human serum albumin (HuSA; B, D, and F) in plasma of female calves from dairy cows with $0-, 30-$, or 60 -d dry period. Values represent means ( \pm SEM) per dry period length (DPL) per week (W).

sessed by an ELISA and results were comparable with previous studies using ELISA [for IgG concentrations; 32.62 (Horn et al., 2010) or $41.5 \mathrm{mg} / \mathrm{mL}$ (Verweij et al., 2014)].

In the present study, cows with a 0-d dry period, but not cows with a $30-\mathrm{d}$ dry period, had lower colos- trum production and lower colostrum immunoglobulin content at first milking compared with cows with a 60-d dry period, which is in line with previous studies (Rastani et al., 2005; Klusmeyer et al., 2009; Verweij et al., 2014). Moreover, it seems that although IgG mass produced at day of calving was lower for cows with 
Table 3. Specific antibody titers for isotopes $\operatorname{IgG}$, IgM, and total immunoglobulin ( $\operatorname{IgT})$ after primary and secondary immunization to keyhole limpet hemocyanin $(\mathrm{KLH})$ and human serum albumin (HuSA) in plasma of female calves $(\mathrm{n}=63)$ from cows with 3 different dry period lengths $(0,30$, or $60 \mathrm{~d} ; \mathrm{LSM})$

\begin{tabular}{|c|c|c|c|c|c|c|c|c|c|c|}
\hline Immunization $^{1}$ & Antibody $^{2}$ & \multicolumn{3}{|c|}{ Dry period length } & SEM & \multicolumn{5}{|c|}{$P$-value ${ }^{3}$} \\
\hline Primary & IgG-KLH & 5.12 & 5.44 & 5.02 & 0.30 & 0.59 & 0.78 & $<0.01$ & 0.34 & 0.61 \\
\hline Primary & IgM-KLH & 6.77 & 6.07 & 6.57 & 0.27 & 0.18 & 0.98 & $<0.01$ & 0.47 & 0.71 \\
\hline Primary & IgG-HuSA & 2.35 & 2.68 & 2.82 & 0.30 & 0.52 & 0.05 & $<0.01$ & 0.92 & 0.73 \\
\hline Primary & IgM-HuSA & 1.43 & 1.76 & 1.51 & 0.25 & 0.64 & 0.95 & $<0.01$ & 0.99 & 0.11 \\
\hline Secondary & IgG-KLH & 8.01 & 7.15 & 7.21 & 0.38 & 0.19 & 0.43 & $<0.01$ & 0.34 & $<0.01$ \\
\hline Secondary & IgM-KLH & 6.99 & 6.48 & 6.84 & 0.24 & 0.33 & 0.26 & 0.17 & 0.18 & 0.41 \\
\hline Secondary & IgG-HuSA & 4.15 & 4.72 & 5.15 & 0.41 & 0.22 & 0.04 & 0.01 & 0.93 & 0.68 \\
\hline Secondary & IgM-HuSA & 1.84 & 1.44 & 1.23 & 0.21 & 0.11 & 0.53 & 0.28 & 0.46 & 0.68 \\
\hline Secondary & IgT-HuSA & 5.42 & 6.21 & 6.77 & 0.48 & 0.13 & 0.01 & $<0.01$ & 1.00 & 0.62 \\
\hline Secondary & IgT-KLH & 6.58 & 5.94 & 5.69 & 0.37 & 0.21 & 0.73 & $<0.01$ & 0.19 & 0.02 \\
\hline
\end{tabular}

${ }^{1}$ Values on primary and secondary immunization are the number after first immunization and the number after second immunization, respectively.

${ }^{2}$ Antibody names are combination of antigen abbreviation and immunoglobulin isotype.

${ }^{3} \mathrm{D}=$ dry period; $\mathrm{P}=$ parity; $\mathrm{W}=$ week.

a 0-d dry period, the total IgG mass produced during colostrogenesis is not different from cows with a 60-d dry period (Baumrucker et al., 2014). This was explained by additional IgG production during the prepartum period for cows with a 0-d dry period compared with cows with a 60-d dry period. This implies that colostrum production for cows with a 0 -d dry period is not compromised, but secretion is distributed over more days, resulting in a lower colostrum secretion at the day of calving (Baumrucker et al., 2014).

Variation in immunoglobulin content in colostrum and milk has been explained by stage of lactation of the cows, milking processes, or milking frequency (Stelwagen et al., 2009). In addition, the current study shows variation between parities. Young cows had lower NAb titers binding HuSA in colostrum than older cows, which is consistent with previous studies (Kruse, 1970; Muller and Ellinger, 1981; Pritchett et al., 1991). Moreover, in the current study natural IgT binding KLH and HuSA were lower in plasma of calves born from young cows than in calves from older cows. The same results were found for SpAb, as the titers of IgT binding HuSA and specific IgG binding HuSA were lower after primary and secondary immunization

Table 4. The response of specific antibody for isotopes IgG, IgM, and total immunoglobulin (IgT) to keyhole limpet hemocyanin (KLH) and human serum albumin (HuSA) in plasma of female calves from cows with 3 different dry period lengths (0, 30, or 60 d; LSM)

\begin{tabular}{|c|c|c|c|c|c|c|c|}
\hline $\begin{array}{l}\text { Increase } \\
(\text { response })^{1}\end{array}$ & Antibody $^{2}$ & \multicolumn{3}{|c|}{ Dry period length } & SEM & \multicolumn{2}{|c|}{$P$-value } \\
\hline \multirow[t]{4}{*}{ First } & Female caves (no.) & 23 & 19 & 21 & & & \\
\hline & IgM-KLH & 1.15 & 0.98 & 0.81 & 0.36 & 0.79 & 0.68 \\
\hline & IgG-HuSA & 2.53 & 2.84 & 3.42 & 0.46 & 0.37 & 0.04 \\
\hline & IgM-HuSA & 0.72 & 0.01 & -0.002 & 0.28 & 0.12 & 0.95 \\
\hline \multirow{5}{*}{ Second } & IgM-KLH & -0.07 & -0.05 & 0.38 & 0.30 & 0.49 & 0.45 \\
\hline & IgG-HuSA & 1.17 & 0.84 & 1.14 & 0.29 & 0.68 & 0.19 \\
\hline & IgM-HuSA & 0.23 & 0.17 & 0.13 & 0.21 & 0.94 & 0.29 \\
\hline & IgT-HuSA & 0.79 & 1.14 & 1.05 & 0.27 & 0.62 & 0.42 \\
\hline & IgT-KLH & 3.39 & 2.22 & 3.16 & 0.34 & 0.05 & 0.04 \\
\hline
\end{tabular}

\footnotetext{
${ }^{a, b}$ Values in the same row with different superscripts differ $(P<0.05)$.

${ }^{1}$ First increase (response) is titers at wk 10 minus titers wk 6 and second increase is titers at wk 11 minus wk 10.

${ }^{2}$ Antibody names are combination of antigen abbreviation and immunoglobulin isotype.
} 
in plasma of calves from young cows than in calves from older cows. Our study is in line with Conneely, et al. (2013), which suggested that older cows are more likely to be exposed to a greater number of antigens in their life (Larson et al., 1980), resulting in more transfer of the antibodies from blood to colostrum and greater antibody titers in plasma of calves. In the present study, all calves received $4 \mathrm{~L}$ of colostrum; hence, intake of NAb by calves may directly reflect the concentration of (natural) IgG and IgM present in the consumed colostrum. The current results show that, albeit calves from cows with a 0-d dry period had lower titers of NAb binding KLH or HuSA in the first $2 \mathrm{wk}$ of life, calves from cows with a 0-d dry period eventually had similar titers of SpAb binding KLH and HuSA both after primary and secondary immunization. This suggests that calves with lower titers of $\mathrm{NAb}$ in the first 2 wk of life mounted a higher SpAb response after primary and secondary immunization than calves with higher titers of NAb in the first 2 wk of life. The titers of NAb may facilitate subsequent specific antibody responses (Lammers et al., 2004). The low level of $\mathrm{NAb}$ and high subsequent antibody response in our study were in line with earlier studies which reported that low NAb titers are related to high levels of SpAb following vaccination or immunization (Sinyakov and Avtalion, 2009) and high NAb titers are related to low SpAb responses (Parmentier et al., 2008). As expected, an IgG response was found after secondary challenge. Secondary IgG response of calves born from cows with a 0 -d dry period was enhanced after secondary immunization.

Higher NAb titers in plasma have been related with higher survival rates and less disease incidence in birds (Star et al., 2007; Sun et al., 2011), fish (Sinyakov et al., 2002; Kachamakova et al., 2006), reptiles (Ujvari and Madsen, 2011), and mammals (Thornton et al., 1994; Ochsenbein et al., 1999). It remains to be studied whether temporarily lowered NAb titers, as found in calves from cows with no dry period in the present study, may have consequences for disease incidence and immune competence of the calves later on. Calves from cows with the 0-d dry period received $47 \%$ less immunoglobulin via colostrum, whereas the calves from cows with a 30 - or 60 -d dry period received $25 \%$ more immunoglobulin than recommended $[100 \mathrm{~g}$ of $\mathrm{IgG}$ by NRC (2001)]. Calves from cows with a 0-d dry period received less $\mathrm{NAb}$ in the colostrum but seem to be able to come to the same level of NAb during the first 6 wk of life; thus, their intrinsic capacity to produce $\mathrm{NAb}$ themselves may be greater than calves from cows with a 30- or 60-d dry period. The data even indicated that calves with low NAb titers mount higher $\mathrm{SpAb}$ responses.
In the current study, omission of the dry period was also accompanied by a shorter pregnancy length and lower birth weight of the calves compared with calves from cows with a $30-$ or 60-d dry period. In agreement with previous studies, in the current study no difference between the 30- and 60-d dry period was noted with respect to pregnancy length (Santschi et al., 2011b) and birth weight of calves (Rastani et al., 2005; Pezeshki et al., 2007). In the present study, no differences in growth and disease incidence of the calves were observed during the observation period of $12 \mathrm{wk}$ of life. The hygiene conditions in our study can be expected to be high. Calves from the present study were all raised at a specific calf-raising farm. This farm is located approximately $15 \mathrm{~km}$ from the main research farm and raises only dairy calves for this specific research farm. The physical environmental conditions, such as housing conditions and the level of hygiene, will influence mortality and morbidity rates, effectiveness of good nutrition, and management programs (Davis and Drackley, 1998). In the present study, no intentional infection was performed; therefore no information on disease resistance was obtained. Apparently, in the current study, omitting a dry period did result in lower immunoglobulin contents and lower NAb titers in colostrum and, as a consequence, low NAb titers during the first $2 \mathrm{wk}$ of life in plasma of the calves without negative consequences for growth and disease incidence during the first 12 wk of life. It can be hypothesized that calves that do not have the ability to recover their NAb levels have more health problems and compromised performance in later life. During the limited observation period of 12 wk, this was not the case. More long-term studies are needed that monitor health of calves from cows that received different dry period lengths under conditions with for example a lower hygiene status.

\section{CONCLUSIONS}

Omitting the dry period of dairy cows resulted in lower plasma NAb titers in calves in the first 2 wk of life compared with calves from cows with a dry period of 30 or $60 \mathrm{~d}$. Lower NAb in plasma of calves was likely caused by lower immunoglobulin content in colostrum compared with calves from cows with a dry period of 30 or $60 \mathrm{~d}$. Lower NAb in plasma did not affect calf growth and SpAb titers. Calves from cows with a $0-d$ dry period showed a greater capacity to produce $\mathrm{NAb}$ themselves in the first $6 \mathrm{wk}$ and showed an increased capacity to mount $\mathrm{SpAb}$ responses, as exemplified during the secondary response. This suggested that calves from cows with a 0-d dry period had earlier immune maturation and had faster response to challenges than other calves. 


\section{ACKNOWLEDGMENTS}

The authors thank the Dutch Dairy Board (PZ; Zoetermeer, the Netherlands), Product Board Animal Feed (PDV; Zoetermeer, the Netherlands), and CRV (Arnhem, the Netherlands) for financing the experiment. The authors also thank the Directorate General of Higher Education, Ministry of National Education, Jakarta, Indonesia, for the scholarship of Novi Mayasari. The authors thank Joop Arts and the staff of Dairy Campus (Lelystad, the Netherlands) for technical support during analysis and experiment.

\section{REFERENCES}

Andersen, J. B., T. G. Madsen, T. Larsen, K. L. Ingvartsen, and M. O. Nielsen. 2005. The effects of dry period versus continuous lactation on metabolic status and performance in periparturient cows. J. Dairy Sci. 88:3530-3541.

Annen, E. L., R. J. Collier, M. A. McGuire, J. L. Vicini, J. M. Ballam, and M. J. Lormore. 2004. Effect of modified dry period lengths and bovine somatotropin on yield and composition of milk from dairy cows. J. Dairy Sci. 87:3746-3761.

Avrameas, S. 1991. Natural autoantibodies: From horror autotoxicus to gnothi seauton. Immunol. Today 12:154-159.

Baumgarth, N., J. W. Tung, and L. A. Herzenberg. 2005. Inherent specificities in natural antibodies: A key to immune defense against pathogen invasion. Springer Semin. Immunopathol. 26:347-362.

Baumrucker, C. R., R. S. Zbinden, H. A. van Dorland, G. J. Remmelink, B. Kemp, A. T. M. van Knegsel, and R. M. Bruckmaier. 2014. Continuous milking of dairy cows disrupts timing of peak IgG concentration appearance in mammary secretions. J. Dairy Res. 81:403-409.

Casali, P., and A. L. Notkins. 1989. CD5+ B lymphocytes, polyreactive antibodies and the human B-cell repertoire. Immunol. Today 10:364-368.

Conneely, M., D. Berry, R. Sayers, J. Murphy, I. Lorenz, M. Doherty, and E. Kennedy. 2013. Factors associated with the concentration of immunoglobulin $\mathrm{G}$ in the colostrum of dairy cows. Animal $7: 1824-1832$

Davis, C. L., and J. K. Drackley. 1998. The Development, Nutrition, and Management of the Young Calf. 1st ed. Iowa State Univ. Press. Ames.

Horn, M. J., M. L. Van Emon, P. J. Gunn, S. D. Eicher, R. P. Lemenager, J. Burgess, N. Pyatt, and S. L. Lake. 2010. Effects of maternal natural (RRR $\alpha$-tocopherol acetate) or synthetic (all-rac $\alpha$-tocopherol acetate) vitamin E supplementation on suckling calf performance, colostrum immunoglobulin $\mathrm{G}$, and immune function. J. Anim. Sci. 88:3128-3135.

Kachamakova, N. M., G. Irnazarow, H. K. Parmentier, H. F. J. Savelkoul, A. Pilarczyk, and G. F. Wiegertjes. 2006. Genetic differences in natural antibody levels in common carp (Cyprinus carpio L.). Fish Shellfish Immunol. 21:404-413.

Klusmeyer, T. H., A. C. Fitzgerald, A. C. Fabellar, J. M. Ballam, R. A. Cady, and J. L. Vicini. 2009. Effect of recombinant bovine somatotropin and a shortened or no dry period on the performance of lactating dairy cows. J. Dairy Sci. 92:5503-5511.

Kruse, V. 1970. Yield of colostrum and immunoglobulin in cattle at the first milking after parturition. Anim. Prod. 12:619-626.

Lammers, A., M. E. V. Klomp, M. G. B. Nieuwland, H. F. J. Savelkoul, and H. K. Parmentier. 2004. Adoptive transfer of natural antibodies to non-immunized chickens affects subsequent antigenspecific humoral and cellular immune responses. Dev. Comp. Immunol. 28:51-60.
Larson, B. L., H. L. Heary, and J. E. Devery. 1980. Immunoglobulin production and transport by the mammary gland. J. Dairy Sci. 63:665-671.

Littell, R. C., G. A. Milliken, W. W. Stroup, and R. D. Wolfinger. 1996. SAS System for Mixed Models. SAS Institute Inc., Cary, NC.

Matter, M. S., and A. F. Ochsenbein. 2008. Natural antibodies target virus-antibody complexes to organized lymphoid tissue. Autoimmun. Rev. 7:480-486.

Muller, L. D., and D. Ellinger. 1981. Colostral immunoglobulin concentrations among breeds of dairy cattle. J. Dairy Sci. 64:1727-1730.

NRC. 2001. Nutrient Requirements of Dairy Cattle: 7th rev. ed. Natl. Acad. Press, Washington, DC.

Ochsenbein, A. F., T. Fehr, C. Lutz, M. Suter, F. Brombacher, H. Hengartner, and R. M. Zinkernagel. 1999. Control of early viral and bacterial distribution and disease by natural antibodies. Science 286:2156-2159.

Oliveira, R. A., C. D. Narciso, R. S. Bisinotto, M. C. Perdomo, M. A. Ballou, M. Dreher, and J. E. P. Santos. 2010. Effects of feeding polyphenols from pomegranate extract on health, growth, nutrient digestion, and immunocompetence of calves. J. Dairy Sci 93:4280-4291.

Parmentier, H. K., G. De Vries Reilingh, and A. Lammers. 2008. Decreased specific antibody responses to alpha-Gal-conjugated antigen in animals with pre-exisitng high levels of natural antibodies binding Alpha-Gal residues. Poult. Sci. 87:918-926.

Parmentier, H. K., A. Lammers, J. J. Hoekman, G. D. V. Reilingh, I. T. A. Zaanen, and H. F. J. Savelkoul. 2004. Different levels of natural antibodies in chickens divergently selected for specific antibody responses. Dev. Comp. Immunol. 28:39-49.

Pezeshki, A., J. Mehrzad, G. R. Ghorbani, H. R. Rahmani, R. J. Collier, and C. Burvenich. 2007. Effects of short dry periods on performance and metabolic status in Holstein dairy cows. J. Dairy Sci. 90:5531-5541.

Ploegaert, T. C. W., G. De Vries Reilingh, M. G. B. Nieuwland, A Lammers, H. F. J. Savelkoul, and H. K. Parmentier. 2007. Intratracheally administered pathogen-associated molecular patterns affect antibody responses of poultry. Poult. Sci. 86:1667-1676.

Ploegaert, T. C. W., E. Tijhaar, T. J. G. M. Lam, A. Taverne-Thiele, J. J. van der Poel, J. A. M. van Arendonk, H. F. J. Savelkoul, and H. K. Parmentier. 2011. Natural antibodies in bovine milk and blood plasma: Variability among cows, repeatability within cows, and relation between milk and plasma titers. Vet. Immunol. Immunopathol. 144:88-94.

Pritchett, L. C., C. C. Gay, T. E. Besser, and D. D. Hancock. 1991. Management and production factors influencing immunoglobulin G1 concentration in colostrum from Holstein cows. J. Dairy Sci. 74:2336-2341.

Rastani, R. R., R. R. Grummer, S. J. Bertics, A. Gümen, M. C. Wiltbank, D. G. Mashek, and M. C. Schwab. 2005. Reducing dry period length to simplify feeding transition cows: Milk production, energy balance, and metabolic profiles. J. Dairy Sci. 88:1004-1014

Santschi, D. E., D. M. Lefebvre, R. I. Cue, C. L. Girard, and D. Pellerin. 2011a. Complete-lactation milk and component yields following a short (35-d) or a conventional (60-d) dry period management strategy in commercial Holstein herds. J. Dairy Sci. 94:2302-2311.

Santschi, D. E., D. M. Lefebvre, R. I. Cue, C. L. Girard, and D. Pellerin. 2011b. Incidence of metabolic disorders and reproductive performance following a short (35-d) or conventional (60-d) dry period management in commercial Holstein herds. J. Dairy Sci. 94:3322-3330.

Sinyakov, M. S., and R. R. Avtalion. 2009. Vaccines and natural antibodies: A link to be considered. Vaccine 27:1985-1986.

Sinyakov, M. S., M. Dror, H. M. Zhevelev, S. Margel, and R. R. Avtalion. 2002. Natural antibodies and their significance in active immunization and protection against a defined pathogen in fish. Vaccine 20:3668-3674.

Srinivasan, A., Y. Ni, and I. Tizard. 1999. Specificity and prevalence of natural bovine antimannan antibodies. Clin. Diagn. Lab. Immunol. 6:946-952. 
Star, L., K. Frankena, B. Kemp, M. G. B. Nieuwland, and H. K. Parmentier. 2007. Natural humoral immune competence and survival in layers. Poult. Sci. 86:1090-1099.

Stelwagen, K., E. Carpenter, B. Haigh, A. Hodgkinson, and T. Wheeler. 2009. Immune components of bovine colostrum and milk. J. Anim. Sci. 87:3-9.

Sun, Y., H. K. Parmentier, K. Frankena, and J. J. van der Poel. 2011. Natural antibody isotypes as predictors of survival in laying hens. Poult. Sci. 90:2263-2274.

Thornton, B. P., V. Větvička, and G. D. Ross. 1994. Natural antibody and complement-mediated antigen processing and presentation by B lymphocytes. J. Immunol. 152:1727-1737.

Tomer, Y., and Y. Shoenfeld. 1988. The significance of natural autoantibodies. Immunol. Invest. 17:389-424.

Ujvari, B., and T. G. Madsen. 2011. Do natural antibodies compensate for humoral immunosenescence in tropical pythons? Funct. Ecol. 25:813-817.

van Knegsel, A. T. M., G. de Vries Reilingh, S. Meulenberg, H. van den Brand, J. Dijkstra, B. Kemp, and H. K. Parmentier. 2007. Natural antibodies related to energy balance in early lactation dairy cows. J. Dairy Sci. 90:5490-5498. van Knegsel, A. T. M., G. J. Remmelink, S. Jorjong, V. Fievez, and B. Kemp. 2014. Effect of dry period length and dietary energy source on energy balance, milk yield, and milk composition of dairy cows. J. Dairy Sci. 97:1499-1512.

van Knegsel, A. T. M., S. G. A. van der Drift, J. Čermáková, and B. Kemp. 2013. Effects of shortening the dry period of dairy cows on milk production, energy balance, health, and fertility: A systematic review. Vet. J. 198:707-713.

Verweij, J. J., A. P. Koets, and S. W. F. Eisenberg. 2014. Effect of continuous milking on immunoglobulin concentrations in bovine colostrum. Vet. Immunol. Immunopathol. 160:225-229.

Vollmers, H. P., and S. Brändlein. 2009. Natural antibodies and cancer. N. Biotechnol. 25:294-298.

Watters, R. D., J. N. Guenther, A. E. Brickner, R. R. Rastani, P. M. Crump, P. W. Clark, and R. R. Grummer. 2008. Effects of dry period length on milk production and health of dairy cattle. J. Dairy Sci. 91:2595-2603.

Zinkernagel, R. M. 2012. Immunological memory $\neq$ protective immunity. Cell. Mol. Life Sci. 69:1635-1640. 